\title{
Mauna Kea - the best choice
}

SIR - In his letter on the site for the UK millimetre wave telescope (Nature 24 March, p.286) Dr H.A. Gebbie stated that the "project was started in the late 1960s" and he recalled a conversation with $\mathrm{Mr}$ J.F. Hosie of the Science Research Council (SRC) to the effect that "funding had been agreed and the delay in building was giving him concern". Until September 1970 I was chairman of the Astronomy Space and Radio Board of SRC and perhaps I may be allowed to place on record the exact sequence of events concerning the millimetre wave project in the late 1960 s.

In January 1968 Professor Graham Smith presented a paper to the Astronomy Committee of the board on the potential importance to astronomy of the millimetre region of the waveband. He advised the committee that "advances in millimetre wave astronomy were not obtainable without considerable cost and some excursion into relatively unexplored fields". The committee set up a working group with Professor Smith as chairman to review the "rewards and difficulties" of a millimetre wave programme. This group began its work in February 1969 and at a meeting of the SRC committee in February 1970, Professor Smith presented his report. The main recommendation was that efforts should be concentrated on providing the best possible instrument for observation in the 8 to $10 \mathrm{~mm}$ range and that to this end " $a$ study of a $30-\mathrm{m}$ compensating reflector should be made". The cost of building a telescope of this type at a remote site was estimated to be greater than $\$ 11$ million. In March 1970 the board accepted the committee's recommendation that certain aspects of the proposal required further research (which it agreed to finance). The 5 year forward look of the board prepared in 1970 for the years 1971-72 to 1975-76 referred to these discussions and the intention to award more grants for the further studies but stated explicitly that no provision has been included for the main facility.

Thus Dr Gebbie's recollections that the project was started or funded in that epoch are correct only in the above limited context. Furthermore, since the discovery of the $2.6 \mathrm{~mm}$ line radiation from galactic carbon monoxide was not made until 1970 (R.W. Wilson et al. Astrophys. J. 161, L43-L44), this can have had no bearing on the issue of the UK facility at that stage.

The development of the proposals eventually leading to the present UK millimetre project belong to a later era and for the historical record the following summary may be of interest. In the spring of 1973 SRC asked Dr J.A. Saxton, the director of the Radio and Space Research Station (later the Appleton Laboratory) to prepare a case for a UK millimetre wave facility. Saxton presented his report to SRC in the summer of 1973. The main proposal was for a $12-\mathrm{m}$ dish to be built by a German firm for working the 2-3 $\mathrm{mm}$ waveband and to be sited at Sutherland in South Africa. By that time pressure was mounting for European collaboration on major scientific projects and SRC convened a "millimetre wave astronomy panel" with Professor A. Hewish as chairman to advise on the situation. When this panel met in January 1974 the general issue had been complicated because collaboration with FrancoGerman and Australian millimetre wave projects was also under discussion.

One problem facing the United Kingdom was the pressure on scientific manpower for any such extensions of its astronomical commitments and in the summer of 1974 R. St J. Walker, secretary of the Science Research Council asked me if we were able to make a substantial contribution to a millimetre wave programme from Jodrell Bank. Since this would have involved the diversion of staff from the development of the multi-telescope system (proposed after the cancellation of the Mk VA telescope) I answered with caution and reserve. However, in the early autumn of 1974 two other factors intervened. SRC agreed to support only the first phase of the multitelescope system (MERLIN) and discussions with UK Atomic Energy Authority (UKAEA), which was acting as agent for the construction of our telescopes, indicated that at a relatively small cost the Mk II telescope at Jodrell Bank could be modified to a 100 foot circular aperture capable of operating down to a wavelength of $6 \mathrm{~mm}$ (the Mk IIA). On 9 October 1974 I despatched to SRC a formal proposal for this work and on the advice of UKAEA asked for $£ 50,000$ for the design study in 1975 , and $£ 1,500,000$ for the construction in 1976-77. This request stimulated SRC to renewed activity and on 11 December 1974 all workers in millimetre wave astronomy were circulated with a request to make proposals for a UK millimetre wave programme.

In order to consider these various proposals, SRC convened a "working group to coordinate proposals on millimetre astronomy" with Professor M.J. Rees as chairman. The major result of the meetings of this group early in 1975 was to recommend that studies should be made for a UK facility capable of operating down to a wavelength of $1 \mathrm{~mm}$. Funds of the order of $£ 100,000$ were made available by SRC for feasibility studies and in the autumn of 1975 SRC established a "UK national millimetre astronomy facility steering committee" under the chairmanship first of T.G. Phillips and later of A. Hewish. By the end of 1975, in the light of the feasibility studies, this steering committee considered that a $15-\mathrm{m}$ aperture telescope to operate down to a wavelength of $0.75 \mathrm{~mm}$ would be feasible.

It was this sequence of events that led to the present proposal approved by SRC in
1980 for a $15-\mathrm{m}$ aperture telescope with a working wavelength limit of $0.3 \mathrm{~mm}$ - that is a telescope one-half the size but working at a wavelength more than 20 times lower than that of the instrument referred to in the 1969 report of Professor Smith's working group.

University of Manchester

Nuffield Radio Astronomy Laboratories, Jodrell Bank, Macclesfield, UK

SiR - H. A. Gebbie (Nature 24 March, p.286) is mistaken in suggesting a "failure to provide a rational basis" for siting the United Kingdom/Netherlands Millimetrewave Telescope on Mauna Kea in Hawaii. The choice was made only after most careful consideration of all the relevant factors by representatives of the British and Dutch millimetre-wave astronomy groups. The evidence on atmospheric absorption was given very great weight in this analysis and it was the outstanding properties of Mauna Kea in this respect which led to its selection.

Gebbie refers to measurements made in 1976 by his group, which reported 'strong excess absorption even in clear dry conditions. Since that time three large telescopes have come into operation on Mauna Kea and it has become established as the world's premier site for astronomical observations at wavelengths near $1 \mathrm{~mm}$ (refs 2-5). Measurements of the atmospheric transmission are made routinely as part of the calibration procedure for such observations. In the clear dry conditions which predominate at this site, the observers report ${ }^{6-13}$ good transmission and do not confirm the excess absorption claimed by Dr Gebbie's group. The general view is that, for submillimetre observations in particular, Mauna Kea is the best site in the world where a major observatory has been established.

To plan the scheduling of the telescope in a way which maximizes its efficiency, we need detailed measurements of the atmospheric transmission covering a long period. We have therefore developed an automated instrument for measuring the sky at wavelengths of around $1 \mathrm{~mm}$. This was installed at the summit of Mauna Kea at the end of 1982 and the data collected so far confirm the excellent properties of the site.

RICHARD HILLS

Cavendish Laboratory,

Cambridge, UK

1. Molfalı, P.. Bohlander, R.A.. MeCrea, W.R. \& (ithbic H.A. Noiure 269, 676 ( 1977$)$

2. Marsther, A.P. Nature 303, 475 (1983).

3. Keenc, J., Hildebrand, R.H. \& W'hileomb. S.F. Astrophvs. J. Lell. 252, 1.11 (1982).

4. Phillips, el al. \& Bcichman. C.A. el al. in Regions of Recent Star Formation (Reidel. Dordricht (19:2).

I.ci, T.J. el al. Nalure 295. 214 (1982).

6. Cunningham, (.T. el al. learus 48,127 (1981).

7. Fellerman, H.R. el al. Science 211, 580 (1981).

8. 1.crurf, J.C.C. (i. Ihesis, (Iniv. I.ondon (1981).

9. Pudman, R., Hills, R.E., Cronin, N.J.\& Rosc, W.B. Mon Not. R. astr. Soc. 192, $87 \mathrm{n}(1980)$

10. Rilcy, P. W. et al. Mon. Not. R. astr. Sex: 199, 197 (1982).

11. Whitc, (i.J., Phillips, J.P. \& W all, (i.I). Mon. Not, R. ustr. Soc: 197,745 (1981).

12. cau Vlict, A.H.F. et at. Astr. Astrophys. 101. 1.1 (1981).

13. Robsesn, i:.l. \& Whitc (i.J. in The Scientific Importance of Submillimetre Ohservations (KSA. Nexrdwijh). 